\title{
SCALES FOR READING VOCABULARY OF PRIMARY CHILDREN
}

\author{
M. E. HAGGERTY \\ University of Minnesota
}

In the Fourteenth Yearbook of the National Society for the Study of Education, ${ }^{\mathrm{I}}$ Superintendent Robinson G. Jones proposed a standard minimum vocabulary for primary reading. He further proposed a "standard test" based on this minimum vocabulary. The test consists of two sets of words, Ir8 "phonetic" and 236 "sight." Each of these sets of words is printed on a card in columns, long-primer type being used. The pupil is tested by being given the card from which he is asked to pronounce the words. The tester notes on a score card each error. The child is scored by a method to be discussed later, each misspelled word being valued by the number of times it occurs in ten primers. In Table I the record for a part of each of two classes for a part of the test is shown. The zeros indicate words missed.

In January, I9I6, the complete test was used under the writer's direction in a number of primary grades (I to III) of the Minneapolis schools and in the training school of one of the Wisconsin state normal schools. The tests were given by the teachers of the several classes who were, at the time, members of the writer's course in educational diagnosis at the University of Minnesota. These teachers at the time had spent a semester studying and giving educational tests and were alive to the necessary experimental conditions that should surround the test. Very specific and oft-repeated directions, both oral and written, were given before the tests were made. The purpose of the test was only secondarily to measure the individuals, classes, or teachers; primarily, it was intended to determine the relative difficulty of the several words of the test. The teachers understood it in this way.

I Part I (I9I5), pp. 39-43. 
In all, about 700 children were tested, the larger part of these being in Grade IB. The results were brought together, tabulated, and the percentage of error on each word was determined. On the basis of the percentage of error, the words were arranged in scaled

\section{TABLE I}

First Grade

\begin{tabular}{|c|c|c|c|c|c|c|c|c|c|c|c|c|c|c|c|c|c|c|c|c|c|}
\hline & & \multicolumn{10}{|c|}{ School A } & \multicolumn{10}{|c|}{ School B } \\
\hline & & \multicolumn{10}{|c|}{ Pupil } & \multicolumn{10}{|c|}{ Pupil } \\
\hline & & I & 2 & 3 & 4 & 5 & 6 & 7 & 8 & 9 & IO & I & 2 & 3 & 4 & 5 & 6 & 7 & 8 & 9 & ro \\
\hline I 86 & tell. & $\cdots$ & & & & & $\ldots$ & & & $\cdots$ & . & $\cdots$ & $\cdots$ & $\ldots$ & . & 0 & & .. & & & \\
\hline 395 & hen... & $\cdots$ & .. & . & . & $\cdots$ & $\ldots$ & 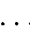 & • & . & . & . & . & .. & $\ldots$ & ... & $\cdots$ & $\ldots$ & $\cdots$ & . & $\ldots$ \\
\hline 4 & mend.. & $\cdots$ & $\cdots$ & . & & . & 0 & & & & & & & $\ldots$ & $\circ$ & $\ldots$ & . & ... & 0 & & \\
\hline 4 & begs.. & $\cdots$ & $\ldots$ & . & & . & ... & . & . & $\ldots$ & & $\cdots$ & $\ldots$ & $\ldots$ & $\ldots$ & $\ldots$ & $\cdots$ & ... & ० & $\ldots$ & \\
\hline 6 & best... & $\ldots$ & 0 & $\ldots$ & & . & $\ldots$ & . & . & 0 & . & $\ldots$ & . & o & $\ldots$ & $\ldots$ & $\ldots$ & $\ldots$ & 0 & $\ldots$ & \\
\hline 34 & dress.. & . & . & ... & $\cdots$ & $\cdots$ & ... & 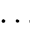 & . & $\cdots$ & $\ldots$ & $\ldots$ & $\cdots$ & ... & $\ldots$ & . . & . & $\ldots$ & $\ldots$ & & \\
\hline I 28 & read. . & . & ... & . . & & & . . & & & $\ldots$ & & & 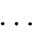 & & 0 & . . & & $\ldots$ & o & . & \\
\hline I 7 & feel.. & $\cdots$ & $\circ$ & $\cdot$ & 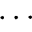 & . & 0 & & & $\circ$ & & & . & . . & $\ldots$ & $\cdots$ & $\cdots$ & 0 & . & . & \\
\hline 204 & beat. & $\ldots$ & o & 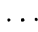 & . & . & 0 & & . & $\circ$ & & $\cdots$ & . & . & $\ldots$ & 0 & 0 & o & $\circ$ & . & \\
\hline 65 & dear. & & & & & & $\ldots$ & & & & & & & & & $\ldots$ & 0 & 0 & o & 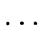 & \\
\hline 25 & been. & & & $\ldots$ & & & . . & & & & & 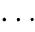 & & & $\ldots$ & o & 0 & 0 & $\circ$ & $\ldots$ & \\
\hline I, IOI & bit... & 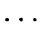 & $\ldots$ & . & & & .. & & & . & & $\cdots$ & & & $\ldots$ & $\ldots$ & 0 & . & $\cdots$ & $\ldots$ & \\
\hline $6 \mathrm{II}$ & still. & & . & & & & $\ldots$ & & & . & & & & & & & $\ldots$ & $\ldots$ & 0 & 0 & \\
\hline I 32 & hid... & . & o & $\ldots$ & . & o & $\ldots$ & . . & $\theta$ & . . & . & $\ldots$ & $\ldots$ & & $\ldots$ & & $\cdots$ & $\ldots$ & 0 & $\ldots$ & \\
\hline 138 & bring.. & & $\cdots$ & & & & 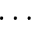 & & & & & $\ldots$ & & & & & . . & $\circ$ & 0 & 0 & \\
\hline
\end{tabular}

groups, the phonetic and sight lists being kept distinct. We thus have two vocabulary scales ranging in difficulty over a series of nine steps for the phonetic words and twelve steps for the sight words. These scales are here appended.

\section{SCALE D}

Line

\section{Phonetic}

45. up home

50. bit cow that out fox would

55. stay ran ill gun like meat ring cut time seed more

6o. pin ball corn swim weep saw ask week meet room

65. hand hot ten must name head cold duck song walk dance deer hole feel joke

70. shake blow hem hop hear fine past sum fire brave late dress air barn mice glass rose jam 
75. dig sled yet trick toy spell frog sent match clap drive find fight flock lad boat sink bank pull dark dish cart charm skip turn bone sale beg teach

8o. brook lid sack grade pride sound rain Rob queen boot roar pail high bar rub cries load

85. crown chew kite snag lace slope rang care nob

\section{SCALE D}

\section{Sight}

45. the war for fly wee I to you said of is a my see do he we are go so

50. come who one she on they away give two help some tree be

55. good your pretty yes too house milk please garden over from by us any bee I'll I'm

6o. have me with this his oh mother very girl over where going if door

65. here has her bird put there no as three shall why basket again flour hungry wolf off brother once window carried these cheese

70. baby what mouse pussy water roll children turkey cry laugh good-by city after began voice their live egg poor many buy free much along soon other county gone happy

75. mamma blue want next wool rabbit sister were great dolly half field soldier squirrel ha eyes dry river every winter first afraid

80. our horse father won't papa bear baa school warm love loaves pony almost lamb middle-sized goose beautiful party owl left Santa Claus bowl hurt

85. bumblebees lion monkey cradle naughty visit caught wagon butcher birthday meadow honey pansy elephant pocket friend

90. oranges daisies iron nibble gobble wash cabbage medal

95. hurrah pigeon circus picnic pieces

Ioo. women

It is interesting to note that certain words partly learned in the first semester persist as problems on into the other grades. Laugh, for example, was known to 73.5 of IB children, but to only 69.2 of IA pupils and only 97 per cent of the IIA's. This tripped I4.5 per cent of the IB's, but also 6.6 per cent of the IIIB's. Middlesized scored percentages of error for the several half-grades of 34.5 , 
$40,20,26, \mathrm{I} 6$, and 3 . Certain pairs of words behave very much alike. The following table shows a number of these.

TABLE II

Percentage of Error

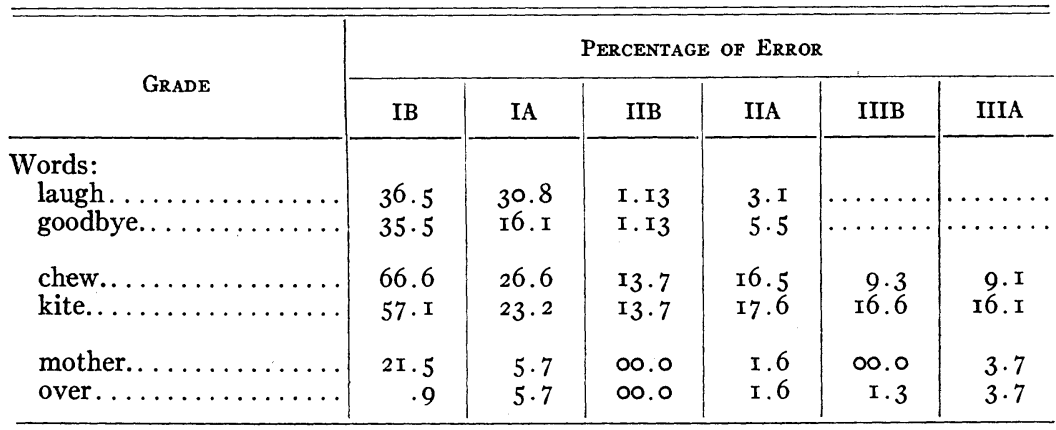

The steps ${ }^{\mathrm{I}}$ on these scales are about 0.3 P.E. which is smaller than necessary for measuring purposes. In practice it is recommended that only alternate steps be used. The selection of words in the following sub-scales, it is thought, will serve practically as well for the testing of an individual or a class as the more complete scales given above.

$$
\text { SCALE } D_{\text {I }}
$$

Line

\section{Phonetic}

50. bit cow that out fox

55. stay ran gun like meat

65. hand ten name head cold

75. yet trick toy frog find

85. crown chew kite snag lace

\section{SCALE DD}

\section{Sight}

50. come who one she on

55. your pretty yes too house

65. here has bird put shall

75. mamma blue next wood rabbit

85. lion monkey cradle naughty visit

95. hurrah pigeon circus picnic pieces

${ }^{x}$ Cf. M. E. Haggerty The Ability to Read: Its Measurement and Some Conditions Determining, Indiana University Bulletin. In press. 
The evident advantage of the $\mathrm{D}_{\mathrm{r}}$ and $\mathrm{DD}_{\mathrm{r}}$ scales is the great saving of time in testing. A single pupil may be adequately tested with both scales in two or three minutes and an entire class of 25 in approximately an hour. The test also obviates the danger from fatigue and distraction of attention on the part of the child when a long test is given.

In using the scales ${ }^{\mathrm{x}}$ for testing purposes the words are printed on a card in columns. This card is handed to the pupil and he is asked to name the words of the first group. When this is done he is asked to name the second group and so on until the words of each line are passed. When the phonetic test has been completed the sight test is given. The errors and omissions are recorded on a specially prepared form. In scoring, a pupil is credited with the highest numbered line in which he achieves but one error or omission. A class is credited with the line in which there is 20 per cent of error. Where no line gives exactly 20 per cent of error, the exact score may be calculated with the help of a table ${ }^{2}$ based on P.E. values in a normal distribution.

How well the scale works may be seen from the results obtained with a class of thirty-five children sixteen weeks after their entrance to school. The facts are shown in Table III.

TABLE III

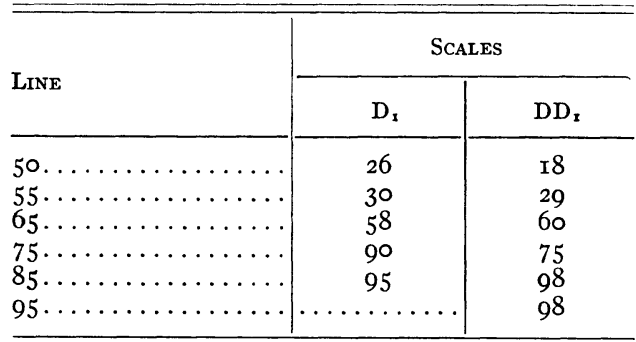

The figures under $\mathrm{D}_{\mathrm{r}}$ and $\mathrm{DD}_{\mathrm{I}}$ represent the percentage of error for the phonetic and sight scales respectively. The scale nature of

I These scales are now printed and for sale by the Northwestern School Supply Co., Minneapolis, Minn.

${ }^{2}$ E. L. Thorndike, Teachers College Record, XVI, 42-43. 
the test is evident from the fact of increasing percentages of error for the upper lines. Considering the small number of cases involved, the ratios are surprisingly near what the scale demands. Calculating the class scores by means of the aforesaid table we find the class rating on scale $\mathrm{D}_{\mathrm{r}}$ to be 47 and on scale $\mathrm{DD}_{\mathrm{r}}$ to be $5^{\mathrm{I}}$. I.

Whether or not these words will maintain the same scale values in further testing will depend chiefly upon whether the children to be tested have met these words and phonograms in their reading the same number of times as had the children from whom these scale values were derived.

Other forces than mere repetition are, to be sure, active. The size of the word, whether it is a very short word like is or to, or a very long word like sunflower; the shape of the word, whether it has letters all of one height or whether it is broken by $p$ 's, $g$ 's, $h$ 's, etc.; the rich mental content brought up by a word like bee or the lack of it attending a word like county; the relation which a word bears to the speaking vocabulary of an individual, whether it names a familiar object like $d o g$ or a remote idea like charm; whether it is intimately related to one's interests as ball is to a boy's play or only remotely as is the word think; the lapse of time since seeing the word, the kind of type and the place on the page in which the child is accustomed to see it-all these factors bear upon the rate and permanency of the child's learning. The necessity for repetition remains, however, no matter what the influence of the other factors, and it is theoretically possible to determine approximately the number of such repetitions necessary for the learning of any word.

How great is the relation between number of repetitions and efficiency of vocabulary is shown by certain correlation figures. These have been figured for three kinds of words. For all words (exclusive of nouns, pronouns, and attributive verbs) yielding 25 per cent or less of error, the coefficient is 0.87 . For the attributive verbs and nouns in the same region of difficulty, both small groups of words, figures are respectively 0.47 and 0.40 . In a general way, our study shows what the number of necessary repetitions for stable learning is. Of all the words in the sight list yielding 2 per cent or less of error only two occurred less than 500 
times. These two are me and of with frequency indices of 482 and 497 respectively. Five hundred repetitions seem very great, especially when we consider that for every recurrence in the text such words received additional oral drill. When you turn to the words with lower frequencies, however, the percentage of error increases very rapidly. At the lower limit with bumblebees, cradle, pony, pansy, and elephant, whose frequencies are 4, Io, 3, 3, and I4, we have 75 per cent of error, and hurrah with 4 occurrences and circus with 3 scored 90 per cent.

We may roughly describe three stages in which words exist in an individual's mind. Let us designate these conditions as well known, barely known, and vaguely recognized. In every mind which can read at all there are some words of each sort. The group of well-known words may be large or small but in any case they are secure. They are the ones which the individual has vastly "overlearned." They have been repeated so often that further exercise upon them does not increase their stability, and continued practice constitutes wasted effort in the process of learning to read. Such words are the and, to, and is, for all normal children who have been to school one semester. For such words learning is essentially complete. They are a sure possession and are ready tools in the acquisition of knowledge and enjoyment from printed pages. The mechanics of reading may be said to be mastered in so far as a wide range of words can be reduced to such a state of automatism.

Quite remote from this is the state in which a word wakens a sense of familiarity but no satisfactorily definite reaction. Instance words on a first or second recurrence. From this condition to that of efficient automatism is a long road and somewhere on the route the words pass through a stage that may be described as that of bare learning. Such words have been clearly recognized once or twice but slip away with an interval of time. The development of efficiency in reading impinges upon words in just this stage of acquisition. A child may worry through a sentence by concentrating upon words, lengthening out the time, mustering his phonetic aids, attempting words and suffering the teacher's correction, but such work is not a mastery of reading technique. The path to mastery is to reduce the words to automatism, to develop the 
neuro-muscular mechanism so that the appropriate vocal utterance or other reaction is immediately incident to the sight of the word. Now, the most effective tool for the development of such mastery is repetition of the word in the individual's experience. Exercise is the instrument which lifts words from the region of the vaguely recognized to that of the barely known and from this twilight zone to the secure automatism characteristic of the efficient reader. The task of giving this exercise under proper conditions and to a sufficient degree is the crucial point in developing ability in vocabulary.

In the process of developing this mastery of reading technique words must be more than learned, if by learning we mean that degree of acquisition which enables the learner barely to recognize and speak the word on the occasion of its recurrence. Practice must go beyond the point of mere reproduction because we know that neural or mental bonds will deteriorate with lapse of time. The individual must be insured against decay, and this insurance is gained by what at the time is superfluous exercise. Exercise must go beyond the point of barely forming the bond. The bonds must be "overlearned."

Now, just what degree of exercise, just what number of repetitions is required to bring any word to any stage of efficiency is known only in the vaguest way. In the program of reading laid down for the IB class in the Minneapolis schools ${ }^{x}$ the word the ${ }^{2}$ occurs 5, I 29 times, doubtless many times the number required to master it. On the other hand, the word picnic appears but 4 times, too few, as our records show, for adequate mastery. Where between these wide extremes is the correct measure for the bare learning and the efficient acquisition of a word we are not able to say.

Some little light may be thrown upon the point by the behavior of the five words, baby, rabbit, great, field, and first. Each of these words was missed by 49 per cent of all the IB Minneapolis children

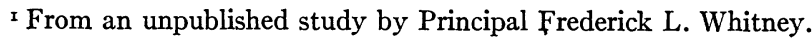

${ }^{2}$ This high frequency is, of course, due to the fact that the is so essential an instrument in the reading of other words. No one believes it must occur so often in order to be learned. 
in our study and properly pronounced by $5^{\mathrm{I}}$ per cent. The fre-

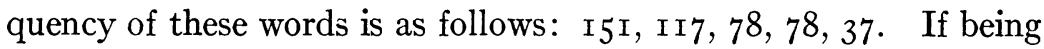
missed by one-half of $\mathrm{I} 89$ children is equivalent to being missed by all of the children one-half of the time, we would have here the number of repetitions required to produce bare learning of these words on the part of these children.

It may not be out of place to call attention to what seems to the writer a fallacious method of grading used by Jones. He makes the amount of error of a child in missing a particular word relative to the number of times that word has occurred in his reading. Similarly, that teacher is less efficient if her pupils miss the more frequently occurring words. He says, "It is a greater error to miss the word 'man' which has a recurrent value of 622 than it is to miss the word 'cap' which has a recurrent value of only I04."

Just why this should be so, Mr. Jones does not state. So far as the writer can see, the validity of such a method must rest upon one of two assumption. It might be correct to penalize a child 622 points for missing the word "man" and only ro4 for missing the word "cap" if the coefficient of one's vocabulary were directly proportional to the number of times he had seen the word. Or it might be considered a more serious deficiency not to know "man" because in the future he would meet it much more frequently and, therefore, his deficiency would appear to plague him more often. The latter alternative can hardly be in mind, because the frequencies given are not for the number of times the word is yet to be experienced. They refer only to what has been. Probably the first assumption is, therefore, the one upon which the method is based, but for the words in Mr. Jones's list, this assumption is far from true. Our test shows that the children knew be as well as who but the frequency of the former is 122 and of the latter is III. The, with a frequency of 5,129, was just as well known and no better than too with a frequency of $\mathrm{I}_{4} 2$. If the proposed method of scoring were to be applied with any degree of accuracy, we should have to know the exact number of repetitions required to learn every word used in the test. This we do not know. The figures given represent frequencies far too few for many of the words; for others 
the amount of "overlearning" is so great that the number of frequencies is out of all proportion to the result. We should also have to know whether the child in question had met the word approximately that number of times. This we might assume if we knew the books studied and the general method followed.

With the scale as worked out in this paper, however, the method becomes superfluous, and its evident fallacy should cause it to be discarded. 